\title{
CONTINUOUS HOLTER MONITORING OF PATIENTS WITH CARDIOVASCULAR DISEASES IN ORAL SURGERY
}

\author{
Daskalov Hr.*, L. Vladimirova-Kitova** F. Nikolov**, E. Sarachev* \\ * Department of Oral surgery, Faculty of Dental medicine \\ ** Department of Cardiology, Faculty of Medicine \\ Medical University - Plovdiv, Bulgaria
}

\section{ABSTRACT}

INTRODUCTION. Pain control and anxiety management are important aspects of modern dental treatment. Although many local anesthetics and anesthesia techniques have so far been studied, there is still no clarity as to what anesthetic should be used in cardiovascularly compromised patients.

This anesthetic and its dosage should be very carefully chosen to achieve optimal effective pain control; the possible side effects occurring mainly in morbidly compromised patients should also be well studied.

METHODS. The aim of this study was to study the effect of vasoconstrictors on local anesthetics in 18 patients with heart diseases.

The study contingent was recruited from the patients visiting often their general dental practitioners and diagnosed with the following heart diseases:

Heart failure (after 6 months); ischemic heart disease, including mild angina pectoris.

Articaine was used as local anesthetic.

RESULTS. The ST segment on the ECG was used to detect myocardial ischemia and to study the effect of the administered local anesthesia.

CONCLUSION. The study results suggest that pain control in a cardiovascularly compromised patient subjected to oral surgery should be carried out only after thorough analysis is conducted of the specific condition and current status of the patient. Additional hematological tests shoud be done to enable the dentist to build a viable treatment plan.

Key words: cardiovascular diseases, Holter, vasoconstrictors;

\section{INTRODUCTION.}

Pain control is a serious problem in medicine. Elimination of pain is essential for a favourable outcome of a treatment. In dental medicine, it is of paramount importance to know as much as possible about how to control pain because the disorders in this field have usually a very painful course due to the dense net of nerve receptors in the maxillofacial region. That is why research in the field of dental anesthesiology is never ceasing globally giving as a result new preparations designed for local anesthesia and development of new methods to administer the various types of anesthesia.

In historical perspectives, the constant search for optimisation of local anesthesia leads to constant synthesis of new drugs designed to improve the efficiency of the anesthetic and reduce at the same time the side effects that were characteristic of previous generations of local anesthetics. It has been found that a combination of a local anesthesia preparation and a vasoconstrictive agent of the group of cathecholamines has a particular good effect. As a result the amount of drug used for anesthesia is reduced considerably. ${ }^{13}$ But local anesthetics have some side effects that are especially pronounced in patients with heart diseases. There have been a number of studies on the drugs used for local anesthesia in these patients. These studies aim at finding what the effects of anesthetics and corrigents are and at developing algorithms for their use and achievement of optimal painless treatment.

A primary requirement in modern dental treatment is that it should be painless. ${ }^{1,8}$ The efficiency of the different types of anesthesia has been well researched, but the problem arising from the use of various anesthetics in patients with heart diseases is still controversial. To achieve an optimal anesthetic effect it is important to select very precisely the type of anesthetic, determine its dose and study very carefully the side effects it may have on the cardiovascular system of patients. There are increasingly frequent reports in the relevant literature of the finding that adding just a little amount of corrigent to the anesthetic does not exert a negative effect on certain cardiovascular diseases, increasing considerably the efficiency of anesthesia at the same time. ${ }^{3,5,6,7,14}$

The aim of the present study was to introduce Holter cardiac monitoring to find what effect vasoconstrictors have on modern local anesthetics in patients with specific heart diseases. 


\section{MATERIAL AND METHODS}

The study included 18 patients planning to have dental surgery; the patients were diagnosed with the following heart diseases: previous myocardial infarction, ischemic heart disease, hypertension and stable stenocardia. The status of the studied patients was ascertained by their medical history and cardiologic tests (coronarography and exercise tolerance test). The principal method used in the study is based on 24-hour recording of ECG using a Holter monitor. The purpose was to use a Holter ECG to establish changes in the cardiac activity during and after anesthesia was administered and the surgery performed. Any pathological changes in the cardiovascular system were detected using the changes in the ST segment of the ECG. Each patient was fitted with an ambulatory electrocardiography device (Holter monitor) in advance; the device was turned on to record the ECG of patients immediately before anesthesia was administered. ${ }^{2,4}$ This was the starting point in the subsequent analysis of the cardiogram. The blood pressure and pulse rate were measured three times prior to, during and after the surgery. We used artcaine as a relatively new preparation. ${ }^{11,12}$

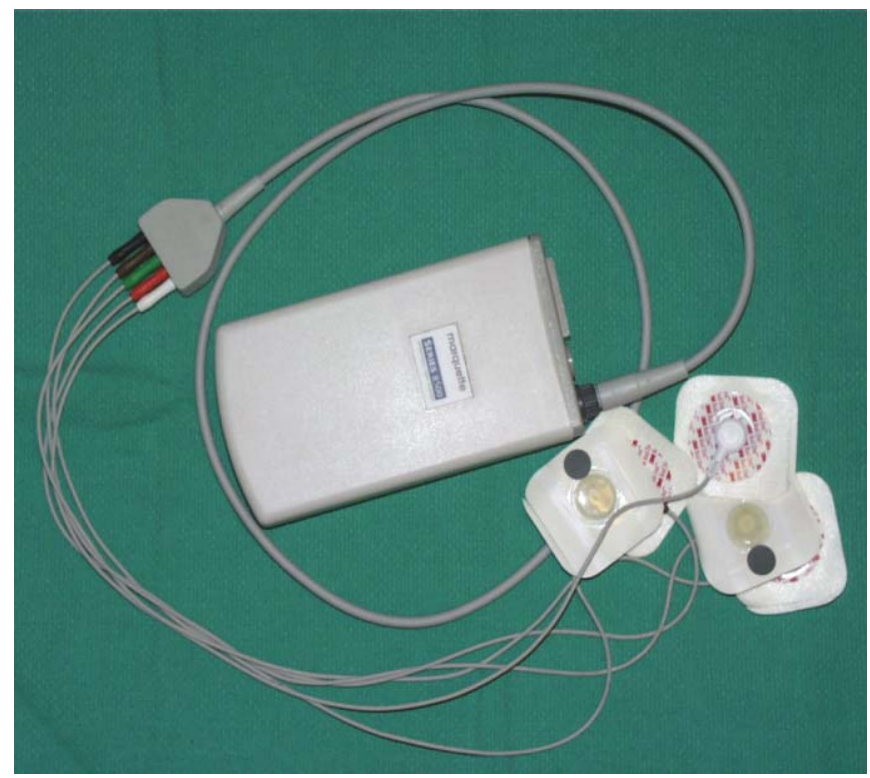

Picture 1. Holder monitor

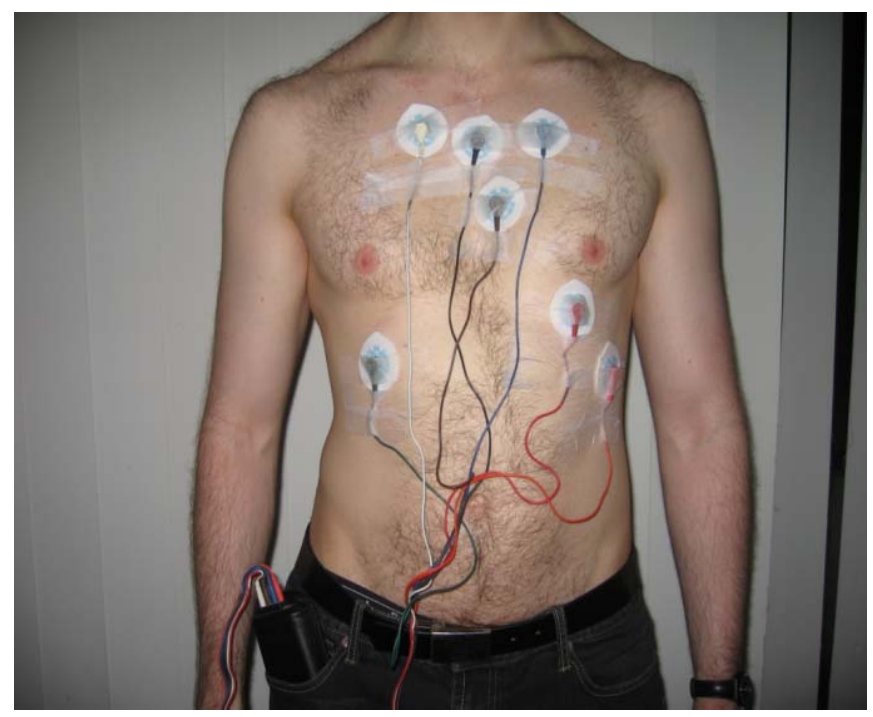

Picture 2. Leads positioning

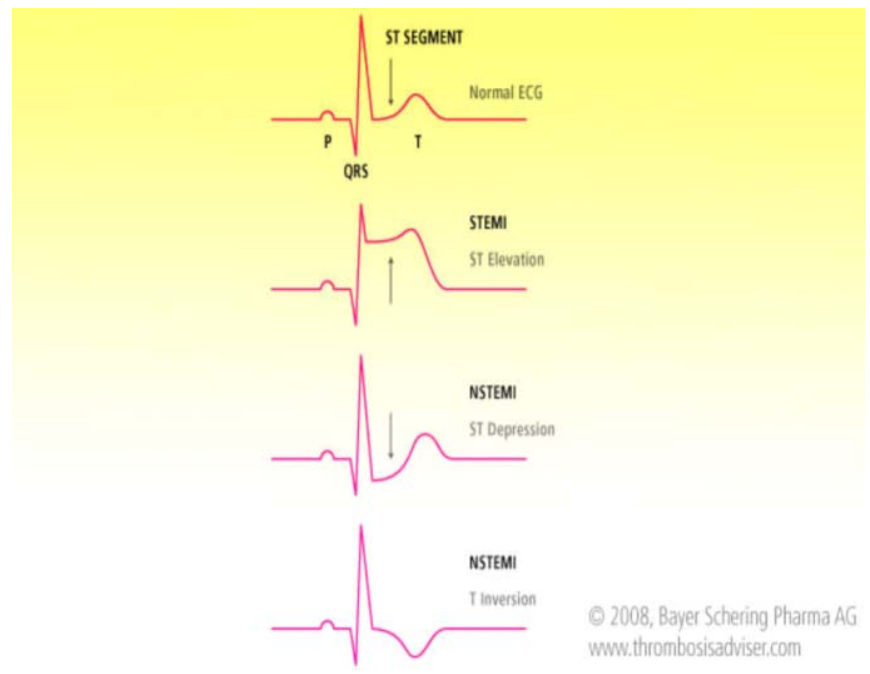

Picture 3. Changes in the ST segment

\section{RESULTS AND DISCUSSION}

The main parameter analysed in this technique is the depression of the ST segment on cardiogram. It is an indicator of a possible ischemic disorder or necrosis in the cardiac muscle. The cardiograms were analysed after completion of the surgical procedures to find any changes in this parameter. We analysed the changes in blood pressure and heart rate. The analysis found no significant depression of the ST segment (greater than $1 \mathrm{~mm}$ ). The blood pressure and heart rate also showed no pathological deviations from baseline values. The anesthesia given to the patients was at a depth at which they felt no pain during surgery. No other events related to the underlying disorders were found. 


\section{CONCLUSION}

The patients we studied showed no significant side effects when anesthetic with a little amount of corrigent was used to anesthetise them. At the same time there was complete lack of pain during the procedure.

\section{REFERENCES:}

1. Michan G. Local anesthesia in dentistry. Medicine publishers Sharov 2003;1-133. (in Bulgarian)

2. Tomov I, L. Tomov. Clinical electrocardiography and vector cardiography. Medicine and Physical culture. Sofia 1981:392. (in Bulgarian)

3. Anisimova EN, Zorian EV, Shuga-lov IA. [The action of Carpule-delivered local anesthetics and their combinations with vasoconstrictors]. Stomatologiia (Mosk). 1998;77(2):19-22. [in Russian] [PubMed]

4. Alemany-Martinez A, ValmasedaCastellon E, Berini-Aytes L, Gay-Escoda C. Hemodynamic changes during the surgical removal of lower third molars. J Oral Maxillofac Surg 2008 Mar;66(3):453-61. [PubMed]

5. Arrigoni J, Lambrecht JT, Filippi A. Cardiovascular monitoring and its consequences in oral surgery. Schweiz Monatsschr Zahnmed. 2005; 115(3):208-13. [in German] [PubMed]

6. Buric N, Tijanic M. Review and analysis of vasoconstrictors in local anesthetics applied in orofacial surgery. Acta Stomatologica Naissi 2003;19(43):315-319.

7. Campbell RL, Langston WG. A comparison of cardiac rate-pressure product and pressure-rate quotient in healthy and medically compromised patients. Oral Surg Oral Med Oral Pathol Oral Radiol Endod. 1995 Aug;80(2):145-52. [PubMed]

8. Glick M, Greenberg BL. The potential role of dentists in identifying patients risk of experiencing coronary heart disease events. J Am Dent Assoc 2005 Nov;136(11);1541-1546. [PubMed]

9. Jowett NI, Cabot LB. Patients with cardiac disease: considerations for the dental practitioner. Br Dent J. 2000 Sep 23;189(6):297-302. [PubMed]

10. Karp JM, Moss AJ. Dental treatment of patients with long QT-syndrome. J Am Dent Assoc 2006 May;137(5);630-637. [PubMed]

11. Malamed S, Gagnon S, Leblanc D. Efficacy of articaine: new amide local anesthetic. J Am Dent Assoc 2000 May;131(5);635-642. [PubMed]

12. Malamed SF, Gagnon S, Leblanc D. Articaine hydrochloride: a study of the safety of a new amide local anesthetic. J Am Dent Assoc. 2001 Feb;132(2):177-85. [PubMed]

13. Malamed S. What's new in local anaesthesia? SAAD Dig. 2009 Jan;25:4-14. [PubMed]

14. Vanderheyden PJ, Williams RA, Sims TN. Assessment of ST segment depression in patients with cardiac disease after local anesthesia. J Am Dent Assoc. 1989 Sep;119(3):407-12. [PubMed]

\footnotetext{
Address for correspondence:

Dr Hristo Daskalov

Medical University - Plovdiv

Faculty of Dental medicine, Department of Oral surgery

E-mail: hdaskalov@hotmail.com
} 